\title{
A empatia na intersubjectividade da relação clínica
}

Sofia Baptista*

\section{RESUMO}

A entrevista clínica é um momento chave na construção da relação médico-doente e desta dependerá largamente a adesão terapêutica futura. Sobejamente se têm debatido as questões éticas relativas à relação clínica, bem como as formas de comunicação verbal e não-verbal utilizadas na consulta médica e principais erros a evitar a este nível. Não obstante, apesar de aparentemente consensual, a prática da empatia por parte do médico tem sido um aspecto raramente explorado e muitas vezes mal interpretado ou gerador de confusões nos campos semântico e lexical.

Palavras-chave: Empatia; Entrevista; Relação Clínica.

\section{DEFININDO EMPATIA}

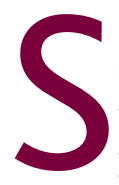
egundo Coulehon et al. a empatia é a «capacidade de perceber a situação, perspectiva e sentimentos do doente e comunicar-lhe essa compreensão». ${ }^{1}$ Uma questão central prende-se com o papel da compreensão neste conceito, encontrando-se autores que inferem que esta significa sentir ${ }^{2}$ o mesmo que o doente e outros que defendem que a empatia poderá constituir uma técnica perfeitamente objectiva e neutral. ${ }^{3}$ Daqui decorrem também três aspectos a distinguir no plano da compreensão clínica:

\section{1) Qual o grau de envolvimento emocional necessário a essa compreensão?}

O psiquiatra Harry Wilmer enfatiza que «se há empatia, há entendimento verdadeiro do outro enquanto pessoa. $»^{5}$ Assim, ao ser empático usamos o próprio enquanto instrumento de compreensão, conseguindo ao mesmo tempo manter a identidade. Para ser empático é necessário, pois, encontrar um ponto de equilíbrio entre o contágio emocional, num extremo, e a sobreintelectualização, no outro. De notar que a empatia não se opõe à objectividade, é antes uma «forma de conhecimento relacional» (Ellen S. More). ${ }^{6}$

* Licenciada em Ciências Básicas da Saúde pela Faculdade de Medicina da Universidade do Porto e aluna do $6 .^{\circ}$ ano do Mestrado Integrado em Medicina da mesma Instituição.

\section{2) Qual o papel da subjectividade do médico?}

Uma compreensão adequada exige uma análise crítica por parte do médico em relação a si mesmo e às suas atitudes, emoções, expectativas e vieses. ${ }^{4}$ No fundo, trata-se de atender ao princípio socrático: «conhece-te a ti mesmo». Não é, pois, desejável - nem possível - uma subtracção das características do médico na complexa equação da relação empática. Pelo contrário, esse auto-conhecimento reforçará as competências de compreensão tão necessárias à empatia, mantendo a independência do juízo clínico.

\section{3) Qual o envolvimento da moralidade?}

Entendida na esfera da moral, a empatia é, simultaneamente, atitude e instrumento para colocar boa intenção na prática médica. ${ }^{4}$ É compreender o doente $\mathrm{e}$ torná-lo consciente dessa compreensão com a intenção de, no seu melhor interesse, colher a sua história e traçar um plano diagnóstico/terapêutico conseguindo da parte do doente melhor informação e adesão.

\section{EMPATIA E SIMPATIA: DOIS CONCEITOS DISTINTOS}

Regressando às raízes etimológicas do Grego, simpatia, derivada de sympatheia, no seu sentido literal, significa sofrer pelo outro e empatia, com origem em empatheia, significa sofrer por dentro. Apesar dos significados terem evoluído com o tempo, a distinção nuclear está patente desde a Antiguidade. Actualmente, enten- 
de-se por simpatia a partilha da emoção expressa pelo outro, que também pode ocorrer na relação médico-doente, quando o clínico partilha das preocupações ou esperanças do doente. No entanto, no contexto da relação clínica, a simpatia é claramente inapropriada, podendo afectar o julgamento clínico. ${ }^{3}$ Com efeito, a simpatia, ao radicar-se no terreno da emoção e compaixão, furta-se à exigência de compreensão inerente e absolutamente necessária ao conceito de empatia.

Por outro lado, de forma cada vez mais consistente, o conceito de empatia é encontrado em documentos oficiais de associações e colégios médicos. No documento Skills for Health, criado em conjunto pela OMS (Organização Mundial de Saúde), UNICEF, UNESCO (Organização das Nações Unidas para a Educação, Ciência e Cultura), Banco Mundial e Fundo das Nações Unidas para a População (UNFPA), a empatia é definida como a capacidade de ouvir e compreender as necessidades e circunstâncias do outro, expressando essa mesma compreensão. É dado particular destaque à importância do treino da empatia pelos estudantes de medicina, quer através da discussão, quer através do método de role play. ${ }^{7}$ Outro exemplo é encontrado na opinião publicada pelo Comité de Ética do Colégio Americano de Ginecologistas e Obstetras (ACOG) sobre a empatia no cuidado da mulher, onde se enfatiza que a empatia é tão importante para a boa prática clínica como outras competências técnicas. ${ }^{8}$

\section{OS CLÍNICOS DEVEM SER EMPÁTICOS?}

Num estudo publicado em Janeiro de 2011 no Journal of the American Board of Family Medicine, envolvendo 40 médicos especialistas em Medicina Geral e Familiar e procedendo-se à gravação das consultas e à aplicação de dois questionários aos doentes no final das mesmas com perguntas relacionadas com a sua satisfação e autonomia, conseguiu estudar-se mais aprofundadamente aquilo que facilmente se intui. ${ }^{9}$ As conclusões principais foram duas: o recurso à empatia associou-se a uma maior satisfação e autonomia por parte dos doentes, o que em potência representa uma melhor adesão terapêutica e motivação para a mudança de comportamentos. De notar que a empatia, recorrendo, entre outras técnicas, à utilização de frases reflexivas, resultou num maior suporte e autonomia percepcionados pelos doentes. A título de exemplo, se um médico pergunta: «está desapontado por não ter perdido peso?», o doente responderá, provavelmente, com um «sim»e, a partir deste pon- to, terá de ser o médico a retomar a conversação; por outro lado, se o médico afirmar: «é de facto difícil perder peso...", o doente terá a oportunidade de comentar esta frase, o que lhe confere mais autonomia e confiança.

É importante ressalvar que a relação empática resulta positivamente, não só para o doente, mas também para o médico, conduzindo a um maior sentido de realização profissional, menores níveis de stress, menor taxa de erros, facilitando ainda a comunicação com doentes à partida mais difíceis. ${ }^{9}$

A empatia não significa colocar-se no «lugar» do doente, aliás importa realçar que, de facto, a compreensão e comunicação dessa compreensão por parte do clínico não implicam que este último experimente ou alguma vez tenha experienciado os mesmos sentimentos que o doente. Não obstante, não sendo uma aptidão clínica inata, a empatia exige treino e esforço para não se cair na prática da simpatia ou do paternalismo. Desde logo, a empatia requer do médico concentração, dependendo de dois elementos não verbais que o clínico deve treinar: por um lado, a descodificação da linguagem não verbal do doente e, por outro, a expressividade, codificando, por assim dizer, de um modo não verbal as suas próprias emoções. ${ }^{9}$

No contexto da entrevista clínica, algumas das estratégias para a comunicação empática passam pelo recurso a frases e questões abertas (por exemplo, «Conte-me um pouco mais sobre isso...» ou «Como se sente em relação a isso?»), bem como expressões que validem os sentimentos do doente e lhe abram uma possibilidade de continuidade discursiva ( $"$ Compreendo que esta situação está a ser muito difícil para si»). ${ }^{8}$ É importante recordar que as pausas no discurso, a escuta terapêutica e a oferta de suporte se constituem também como fulcrais para a empatia na relação clínica. Assim, barreiras à empatia tantas vezes presentes, como um local inadequado para a consulta, pouca disponibilidade de tempo ou linguagem contendo muitos termos técnicos, deverão ser prontamente identificadas e evitadas. ${ }^{3}$

\section{ILAÇÕES FINAIS}

No encontro de subjectividades que é o terreno da relação clínica, a empatia, na sua definição essencial, funda-se sobre dois alicerces fundamentais: um deles é a compreensão, por parte do médico, do doente, suas emoções, vivências, dúvidas e medos, o que corresponde a um processo que, sendo intrapsíquico, não é 
observável; o outro, a dimensão observável da empatia, refere-se à capacidade do médico reflectir e expressar essa mesma compreensão ao doente.

Quer a nível semântico quer prático, por vezes é erroneamente assumida a existência de sinonímia entre empatia e simpatia. Interessa, portanto, marcar com clareza a distinção entre os dois conceitos: na simpatia, existe a partilha de um sentimento; não obstante, tal partilha não obriga ao esforço da compreensão nem à comunicação dessa mesma compreensão, aspectos que definem de modo fundamental a empatia.

Com efeito, a empatia constitui um instrumento e atitude basilares para o modelo de entrevista clínica centrada no doente. Uma entrevista aberta em que se faça uso de comunicação empática permite um conhecimento mais aprofundado por parte do médico de todo o espectro de factores de risco, sintomas e problemas de cada doente e, deste modo, reforça a autonomia, satisfação e confiança do doente no médico, aumentando a probabilidade de adesão às recomendações para modificação de factores de risco e/ou ao plano terapêutico delineado. A prática da empatia também se repercute positivamente no clínico, que poderá sentir-se mais realizado profissionalmente e menos susceptível aos efeitos do stress.

Em suma, a empatia, enquanto demonstração de entendimento por parte do médico das perspectivas do doente, revela-se uma ferramenta poderosa, que constitui um reforço da relação terapêutica e facilita a gestão de emoções. Como refere José Nunes, baseado no método clínico de Carl Rogers, «a sensação de ser compreendido pelo outro é, em si, intrinsecamente terapêutica: quebra as barreiras do isolamento da doença ou do mal-estar e restaura a sensação de se sentir como um todo.» ${ }^{10}$

Assim entendida, a prática da empatia deveria, cla- ramente, estar incluída de modo sistematizado no curriculum médico.

\section{REFERÊNCIAS BIBLIOGRÁFICAS}

1. Coulehan JL, Platt FW, Egener B, Frankel R, Lin CT, Lown B, et al. "Let me see if I have this right...": words that help build empathy. Ann Intern Med 2001 Aug 7; 135 (3): 221-7.

2. Marchand M. Should family physicians be empathetic? No. Can Fam Physician 2010 Aug; 56 (8): 745-7.

3. Lussier MT, Richard C. Should family physicians be empathetic? Yes. Can Fam Physician 2010 Aug; 56 (8): 741-2.

4. Gelhaus P. The desired moral attitude of the physician: (I) empathy. Med Health Care Philos 2012 May; 15 (2): 103-13.

5. Wilmer HA. The doctor-patient relationship and the issues of pity, sympathy and empathy. Br J Med Psychol 1968 Sep; 41 (3): 243-8.

6. More ES. Empathy as a hermeneutic practice. Theor Med 1996 Sep; 17 (3): 243-54.

7. WHO / UNESCO/UNICEF/UNFPA/World Bank. Skills for health: skillsbased health education including life skills: an important component of a child-friendly/health-promoting school. 2003. Disponível em: http://www.who.int/school_youth_health/media/en/sch_skills4health_ 03.pdf [acedido em 31/05/2012].

8. American College of Obstetricians and Gynecologists Committee on Ethics. Committee Opinion No. 480: Empathy in women's health care. Obstet Gynecol 2011 Mar; 117 (3): 756-61.

9. Pollak KI, Alexander SC, Tulsky JA, Luyna P, Coffman CJ, Dolor RJ, et al. Physician empathy and listening: associations with patient satisfaction and autonomy. J Am Board Fam Med 2011 Nov-Dec; 24 (6): 665-72.

10. Nunes JM. Comunicação em Contexto Clínico. Lisboa: Bayer Health Care; 2007. pp. 53-55.

\section{CONFLITOS DE INTERESSES}

A autora declara não existir qualquer conflito de interesse.

\section{ENDEREÇO PARA CORRESPONDÊNCIA}

R. de Manuel Bandeira, 147, hab. 23. 4150-479 Porto

E-mail: med06188@med.up.pt

Recebido em 01/02/2012

Aceite para publicação em 03/06/2012

\section{ABSTRACT}

\section{EMPATHY IN THE DOCTOR-PATIENT RELATIONSHIP}

The clinical interview is a key element in the construction of the doctor patient relationship. It can influence adherence to therapy. Ethical issues in the doctor-patient relationship, verbal and non-verbal communication, and errors to avoid in clinical communication have been widely discussed. However, despite agreement regarding its importance, the concept of physician empathy is rarely explored and may be misinterpreted or cause confusion.

Keymords: Empathy; Interview; Physician-patient Relations. 